\title{
SIMBOL DAN AKIDAH ISLAM \\ Analisis Semiotik terhadap Serat Darmasonya Karya KPH Suryaningrat
}

\author{
Nurul Baiti Rohmah \\ Alumna Magister Ilmu Susastra Universitas Diponegoro
}

\begin{abstract}
Serat Darmasonya written by KPH Suryaningrat was a manuscript using Javanese language and letter, and also in the form of tembang macapat. In its development, Serat Darmasonya was transliterated into the Latin letter and translated into Indonesian language by Suratmin in 1981 and published by Proyek Penerbitan Buku Sastra Indonesia dan Daerah. Transliteration and translation of the manuscript aimed to help the readers especially and the manuscript researchers generally to comprehend its content. Serat Darmasonya contains akidah (beliefs) based on rukun iman in Islam (the five Islam pillars). Islam belief is to believe in the singleness of Allah, the Only One God and the difference between Allah as the Creator and His creatures; the positions, jobs, and form of His angels; the existence of His holy books that are Taurat, Zabur, Injil, and Al-Quran; the prophets as His messengers; the Day of Resurrection; and both good and bad things which happen as His will. The purpose of this study is to reveal the symbols of Islam beliefs contained in Serat Darmasonya. Finding the answer of the research problems, semiotics approach based on Riffaterre's semiotics theory was used. Basically, this study is a library research. The research data were obtained from the textual sources related to the research object. The result study showed that Serat Darmasonya written by KPH Suryaningrat used the elements of indirection, both as displacing, distorting, and creating meaning. According to heuristics and hermeneutics reading and interpretation, matrics identification, model, variance, and hypogram, it can be concluded that Islam beliefs in Serat Darmasonya manuscript is believing in Allah, His angels, His holy books, His messengers, the Judgement day, and His will (predestination).
\end{abstract}

Key Words: religion, Islam beliefs, semiotics, symbol.

\section{Pendahuluan}

Pengaruh globalisasi terkadang belum tentu cocok dan baik untuk bangsa Indonesia. Padahal, pola kehidupan nenek moyang bangsa Indonesia yang luhur dapat ditemukan dalam naskah-naskah lama. Salah satu naskah lama adalah Serat Darmasonya (selanjutnya disingkat $S D$ ) karya KPH Suryaningrat, yang berisi tentang akidah-akidah yang bersumber pada enam rukun iman dalam agama Islam yakni iman kepada Allah, iman kepada malaikat, iman kepada kitab Allah, iman 
kepada rasul, iman kepada hari kiamat, dan iman kepada kehendak Allah. Keseluruhan rukun iman ini terdapat dan terkandung dalam $S D$ karya KPH Suryaningrat.

Pada perkembangannya, SD karya KPH Suryaningrat ini mengalami reproduksi yakni ditransliterasikan ke dalam huruf latin dan diterjemahkan ke dalam bahasa Indonesia oleh Suratmin pada tahun 1981 yang diterbitkan oleh Proyek Penerbitan Buku Sastra Indonesia dan Daerah. Teks SD karya KPH Suryaningrat yang telah ditransliterasi dan diterjemahkan oleh Suratmin ini perlu dikaji lebih mendalam agar nilai-nilai ajaran Islam, khususnya akidah Islam yang terkandung di dalamnya, dapat dipahami oleh masyarakat luas. Pertanyaan yang dibahas dalam studi ini adalah, seperti apakah simbol dan akidah Islam yang terkandung dalam $S D$ ?

\section{Landasan Teori}

Untuk memahami dan memecahkan masalah dalam studi ini, penulis menggunakan teori semiotik yang dikemukakan oleh Michael Riffaterre. Pemaknaan puisi secara semiotik menurut Riffaterre dalam bukunya Semiotics of Poetry (1978) meliputi empat hal pokok sebagai langkah pengungkapan makna.

Pertama, ketidaklangsungan ekspresi yang disebabkan oleh adanya penggantian arti (displacing of meaning), penyimpangan arti (distorting of meaning), dan penciptaan arti (creating of meaning). Kedua, pembacaan heuristik dan pembacaan hermeneutik. Pembacaan heuristik adalah pembacaan pada taraf mimesis atau pembacaan yang didasarkan konvensi bahasa, sehingga pembaca harus memiliki kompetensi linguistik agar dapat menangkap arti (meaning). Kompetensi linguistik yang dimiliki oleh pembaca itu berfungsi sebagai sarana untuk memahami beberapa 
hal yang disebut sebagai ungramatical (ketidakgramatikalan teks). Pembacaan ini juga disebut dengan pembacaan semiotik pada tataran pertama. Dalam pembacaan pada tataran ini, masih banyak arti yang beraneka ragam, makna yang tidak utuh, dan ketidakgramatikalan. Untuk itu, pembacaan pada tataran ini masih perlu dilanjutkan ke pembacaan tahap kedua. Pembacaan tataran kedua yang dimaksud adalah pembacaan hermeneutik. Pada pembacaan ini akan terlihat hal-hal yang semula tidak gramatikal menjadi himpunan kata-kata yang ekuivalen (Riffaterre, 1978:5-6).

Ketiga adalah penentuan matriks, model, dan varian. Matriks adalah kata kunci (keyword). Model berupa kiasan. Matriks dan model ditransformasikan menjadi varian-varian. Varian-varian itu berupa masalahnya. Dari matriks, model, dan varian-varian ini, dapat disimpulkan atau diabstraksikan tema sajak (karya sastra).

Yang keempat adalah prinsip intertekstual. Prinsip intertekstual adalah prinsip hubungan antarteks sajak. Dalam hal ini, mau tidak mau terjadi proses transformasi teks yang dikenal dengan istilah hipogram. Riffaterre (1978: 2) mendefinisikan hipogram sebagai teks yang menjadi latar atau dasar penciptaan teks lain.

\section{Metode}

Metode yang digunakan dalam studi ini terdiri dari pengumpulan data, analisis data, dan penyajian hasil analisis data. Pengumpulan data dalam tulisan ini menggunakan metode kepustakaan (library research). Pemilihan metode kepustakaan dilakukan dengan pertimbangan bahwa data dan sumber data yang dianalisis diperoleh dari sumber-sumber tertulis yang terkait dengan objek yang diteliti yang berupa data 
primer dan data sekunder. Data primer studi ini adalah $S D$ karya $\mathrm{KPH}$ Suryaningrat. Dalam hal ini, SD yang digunakan adalah hasil transliterasi dan terjemahan Suratmin dan diterbitkan oleh Proyek Penerbitan Buku Sastra Indonesia dan Daerah pada tahun 1981. Data sekunder studi ini adalah buku, jurnal, dan hasil studi sebelumnya yang berhubungan dengan data primer. Pada tahap analisis data, yang penulis lakukan adalah sebagai berikut. Pertama, penulis membaca teks $S D$ yang sudah ditransliterasi dan diterjemahkan oleh Suratmin dengan cermat. Kedua, penulis menganalisis simbol-simbol akidah Islam yang terkandung dalam $S D$. Dalam hal ini, penulis mengaplikasikan analisis struktural semiotik yang ditawarkan Riffaterre dalam bukunya Semiotics of Poetry (1978). Ketiga, penulis menganalisis akidah Islam yang terkandung dalam $S D$. Keempat, penulis menyimpulkan dan melaporkan hasil penelitian dalam bentuk artikel jurnal. Pada tahap penyajian hasil analisis data, studi ini menggunakan bentuk deskripsi.

\section{Ketidaklangsungan Ekspresi}

Ketidaklangsungan ekspresi disebabkan oleh tiga hal yaitu: penggantian arti (displacing of meaning), penyimpangan arti (distorting of meaning), dan penciptaan arti (creating of meaning). Penggantian arti disebabkan oleh metafora dan metonimia (Riffaterre, 1978:2). Metafora dan metonimia adalah bahasa kiasan pada umumnya, seperti perbandingan, pemanusiaan, penyebutan sebagian, dan metonimia. Keempat bahasa kiasan tersebut diuraikan sebagai berikut.

\section{1. Perbandingan}

Perbandingan merupakan sejenis bahasa kiasan yang menyamakan dua hal secara umum berbeda. Perbandingan ini dapat dikelompokkan menjadi simile, metafora, 
dan litotes. Penggunaan gaya bahasa perbandingan pada teks $S D$ dalam rangka fungsi intensitas makna dan memberikan gambaran konkret.

Penggunaan simile terdapat pada pupuh Asmaradana bait 15. Pupuh tersebut secara umum membahas mengenai hari kiamat. Adanya matahari yang terbit dari barat dan terbenam di sebelah timur, merupakan simbol datangnya hari kiamat.

Metafora tampak pada pupuh Asmaradana bait 34. Penggunaan metafora pada teks tersebut, tampak pada frasa sirahing salat (kepalanya salat) pada baris 5 . Surat Al-Fatihah sebagai kepala salat memiliki makna bahwa surat tersebut merupakan "bacaan utama dalam salat".

Penggunaan litotes terdapat pada pupuh Sinom bait 46 yaitu pada frasa apem jagung yang diartikan makanan yang biasa-biasa saja. Teks tersebut berisi tentang kesederhanaan nabi Sulaiman.

\section{2. Pemanusiaan}

Bentuk pemanusiaan adalah personifikasi. Penggunaan gaya bahasa personifikasi dalam rangka fungsi menghidupkan suasana yang dilukiskan. Contohnya terdapat pada pupuh Asmaradana bait 15 yakni tampak pada kalimat arga sontarung samyarga (gunung berlaga dengan sesama gunung). Teks tersebut berisi tentang datangnya hari kiamat yang disimbolkan dengan adanya gunung yang berlaga dengan sesama gunung. Gunung disini diibaratkan seperti manusia yang sedang berlaga.

\section{3. Penyebutan Sebagian}

Bentuk penyebutan sebagian berupa sinekdoke. Sinekdoke adalah bahasa kiasan yang menyebutkan suatu bagian yang penting suatu benda (hal) untuk benda (hal 
itu sendiri). Penggunaan gaya bahasa penyebutan sebagian pada teks $S D$ dalam rangka fungsi memberikan gambaran yang konkret terhadap objek yang dilukiskan. Sinekdoke dibedakan menjadi dua yaitu sinekdoke pars pro toto dan totum to parte. Sinekdoke pars pro toto terdapat pada pupuh Dhandhanggula bait 14. Penggunaan sinekdoke pars pro toto, tampak pada kata sireku (Anda) pada baris 4. "Sireku" (Anda) ini menyatakan sebagian untuk menyebutkan keseluruhan yakni umat muslim yang beriman. Simbol umat yang beriman adalah percaya terhadap sifatsifat Allah Swt. yaitu Allah Maha Hidup, Allah Maha Mengetahui, dan Allah Maha Berkendak. Penggunaan sinekdoke totum pro parte terdapat pada pupuh Dhandhanggula bait 11. Penggunaan sinekdoke tersebut, tampak pada frasa nem prakareku (enam hal itu). "Nem prakareku" (enam hal itu) adalah simbol rukun iman yang berjumlah enam yaitu iman kepada Allah, iman kepada malaikat, iman kepada kitab Allah, iman kepada rasul, iman kepada hari kiamat, dan iman kepada takdir Allah.

\section{4. Metonimia}

Metonimia merupakan suatu gaya bahasa yang menggunakan sebuah kata untuk menyatakan suatu hal lain. Penggunaan gaya bahasa metonimia pada $S D$ dalam rangka fungsi menghidupkan suasana yang dilukiskan. Penggunaan metonimia tampak pada kata sebab (sebab) pada pupuh Dhandhanggula bait 23. Teks tersebut berisi tentang keagungan sifat-sifat Allah Swt. yang menjadikan-Nya menyatu dengan makhluk-Nya. Simbol keagungan Allah ditunjukkan dengan sifat-Nya sebagai Hyang Mulia, tiada berubah dan bergerak, tiada berhenti dan berjalan, karena Allah memiliki sifat yang berbeda dengan makhluknya. 
Penyimpangan arti terjadi bila ada tiga hal yaitu: ambiguitas, kontradiksi, dan nonsense. Untuk memperjelas ambiguitas dan kontradiksi, berikut uraiannya.

\section{5. Ambiguitas}

Bahasa dalam karya sastra sering mempunyai arti ganda. Hal ini akan menimbulkan banyak penafsiran dalam mengartikannya. Sifat banyak tafsir ini disebabkan oleh penggunaan kata-kata kias dan ambigu. Ambiguitas ini dapat berupa kata, frase, klausa, maupun kalimat yang mempunyai makna ganda. Hal ini dikarenakan oleh panggunaan kata-kata, frase, klausa, atau kalimat yang bermakna lebih dari satu. Ambiguitas dalam karya sastra akan memberi kesempatan kepada pembaca untuk memberikan arti sesuai dengan penafsirannya. Ambiguitas terdapat pada pupuh Dhandhanggula bait 8 . Penggunaan ambiguitas tersebut, tampak pada kalimat ing wong makmin tatkalanira ngabekti, tan kowang yen tan mangan (orang mukmin ketika berbakti, tidak bisa pisah bila tidak makan) pada 9-10. Teks tersebut memiliki beberapa makna yaitu orang mukmin yang hendak beribadah kepada Allah hendaknya makan terlebih dahulu dan ibadah kepada Allah sebaiknya lebih di utamakan.

\section{6. Kontradiksi}

Salah satu cara untuk menyatakan arti atau makna secara kebalikan digunakan bahasa kias, misalnya ironi dan paradoks. Penggunaan gaya bahasa ironi pada teks $S D$ dalam rangka fungsi mengkritik. Penggunaan ironi tampak pada pupuh Kinanthi bait 21. Penggunaan ironi tersebut, tampak pada kata gumиуи (tertawa) pada baris 4 dan pada kata nangis (menangis) pada baris 6. Teks tersebut menjelaskan mengenai balasan Allah kepada hamba-Nya. Kata "gumuyu" (tertawa) merupakan simbol lebih mengutamakan keduniawian yang diliputi dengan napsu- 
napsu. Umat muslim yang di dunianya lebih mengutamakan hal-hal yang bersifat keduniawian, kelak akan "nangis" (menangis) di akhirat. "Nangis" merupakan simbol siksaan Allah Swt. di neraka.

Penggunaan gaya bahasa paradoks pada teks $S D$ untuk menghidupkan suasana yang dilukiskan. Penggunaan paradoks terdapat pada pupuh Kinanthi bait 22-23. Secara keseluruhan teks tersebut menunjukkan tentang gambaran balasan Allah Swt. kepada umat-Nya. Penggunaan paradoks, tampak pada kata wareg (kenyang) pada pupuh Kinanthi bait 22 baris 1 yakni pada kalimat "wong wareg aneng dunyeku neng akerat dadi ngelih" (sesungguhnya orang yang kenyang di dunia, di akhiratnya menjadi lapar). Kata “wareg” merupakan simbol kenyang akan nikmat dunia dan "ngelih" merupakan simbol lapar akan nikmat akhirat. Jadi umat muslim yang di dunianya mengutamakan nikmat keduniawian yang bersifat sementara, maka di akhirat akan marasa kekurangan nikmat akhirat yang bersifat kekal yakni surga dan yang didapatkan hanya siksa neraka.

Penciptaan arti merupakan konvensi kepuitisan yang berupa bentuk visual yang secara linguistik tidak mempunyai arti, tetapi menimbulkan makna dalam sajak (dalam karya sastra). Yang termasuk di dalam penciptaan arti ini adalah pola persajakan, enjambement, tipografi, dan homologues.

\section{7. Pola Persajakan}

Pola persajakan meliputi asonansi, aliterasi, sajak awal, sajak akhir, sajak tengah, dan sajak dalam. Pola persajakan tersebut dalam rangka fungsi menimbulkan orkestrasi bunyi atau keselarasan bunyi sehingga maknanya selaras.

\section{8. Enjambement}


Enjambement bermakna perloncatan baris pada sajak. Contohnya terdapat pada pupuh Dhandhanggula bait 17. Teks tersebut menunjukkan bahwa Allah Maha Mendengar dan Maha Mengetahui. Penggunaan enjambement pada teks tersebut untuk memberi makna liris, mengeraskan arti, dan memusatkan perhatian pada kata-kata berikutnya.

\section{9. Tipografi}

Tipografi berarti penyusunan baris-baris dalam keseluruhan sajak. Sajak-sajak dalam teks $S D$ secara umum tidak mengunakan tipografi khusus. Semuanya diungkapkan dalam bait-bait seperti umumnya puisi lama yang berbentuk tembang macapat yang mempunyai aturan-aturan yang bersifat mengikat. Penggunaan tipografi pada teks tersebut untuk memberikan gambaran yang konkret pada objek yang dilukiskan dan mengeraskan makna. Contohnya terdapat pada pupuh Dhandhanggula bait 16 . Teks tersebut berisi tentang perbedaan manusia dengan ciptaan Allah lainnya.

\section{10. Homologues}

Homologues adalah bentuk kata yang sama pada baris-baris yang sejajar. Homologues terdapat pada pupuh Sinom bait 10. Pada teks tersebut ada persejajaran bentuk yang menimbulkan persejajaran arti. Hal ini tampak pada kalimat "sing sapa sengit marang, malaekat memaoni, tan anacat memisuh kawetu lesan” (yang benci kepada malaikat dan mencela, mencerca, dan mencaci maki). Kata "sengit" (benci) secara linguistik berbeda dengan kata "memaoni” (cela). Setelah pengarang menyejajarkan bentuknya, terjadilah arti bahwa bentuk kebencian dapat berupa mencela. Teks tersebut secara keseluruhan berisi tentang adanya malaikat. 


\section{Pembacaan Heuristik}

Pembacaan heuristik adalah pembacaan yang didasarkan pada konvensi bahasa. Berikut pembacaan heuristik pupuh Dhandhanggula, bait 2-3. Umat muslim akan mendapat kasih sayang dari Allah Swt. setelah berpedoman pada empat hal yakni dalil, hadis, kias, dan ijmak. Jika ada ilmu yang menyimpang dari empat hal tersebut, ilmunya termasuk ilmu setan dan secepatnya wajib dibunuh. Selain empat hal tersebut, lebih sempurna lagi bila berpedoman pada iman, tauhid, makrifat, dan keempatnya Islam.

Selanjutnya pembacaan heuristik pupuh Dhandhanggula bait 4. Allah hanya satu. Bagi orang yang menduakan-Nya termasuk golongan orang kafir. Dalam sebuah firman Allah Swt. dijelaskan bahwa orang kafir kelak mendapat siksa di neraka.

Pembacaan heuristik pupuh Dhandhanggula bait 18-20 adalah Allah Swt. sebagai pencipta berbeda dengan ciptaan-Nya yakni manusia. Allah Swt. kaya ilmu namun tanpa akal budi, melihat tanpa dengan mata, mendengar tanpa dengan telinga, bersabda tanpa dengan bibir dan mulut, dan tiada bersuara pula. Allah juga tidak bisu, tidak bertambah dan berkurang. Allah tidak berwarna, tidak berbentuk, dan juga tidak berbau. Sangat berbeda dengan makhluk ciptaan-Nya khususnya manusia. Manusia mengalami hidup dan mati, tinggi dan rendah, sakit dan enak, kosong dan penuh.

Adapun pembacaan heuristik pupuh Sinom bait 12 adalah setiap malaikat memiliki kedudukan dan tugas masing-masing. Kedudukannya ada yang besar. Tempat duduknya pun ada yang melingkari tempat kedudukan Allah Swt. Ada pula malaikat yang menyakiti dirinya sendiri. Malaikat memiliki tugas menjatuhkan air, 
menghembuskan angin, dan memecahkan biji. Setiap biji, dipecahkan oleh satu malaikat.

Selanjutnya pembacaan heuristik pupuh Sinom bait 14. Malaikat satu dengan lainnya berbeda. Ada malaikat yang bersatu ada pula yang berpisah. Malaikat juga bisa menyamar menjadi hewan-hewan suci seperti manusia, menjangan, kerbau, kambing, sapi, unta, kuda, burung, segala hewan yang suci dan bagus.

Pembacaan heuristik pada pupuh Dhandhanggula bait 11-12 sebagai berikut. Kitab Subah menyebutkan bahwa iman yang sempurna adalah iman yang tulus dari hati dan percaya kepada rukun iman yakni diawali dengan percaya kepada Allah Swt. dan percaya pada malaikat. Rukun iman ketiga adalah percaya pada kitab Al-Quran dan mengagungkannya. Orang mukmin yang mencintai AlQuran berarti sama saja mencintai kitab-kitab sebelumnya. Rukun iman keempat adalah percaya kepada para nabi. Rukun iman kelima adalah percaya adanya hari kiamat dan rukun iman keenam adalah percaya pada kodrat Allah, baik berupa tinggi rendah, besar kecil, dan baik buruk. Semua itu merupakan kehendak dari Allah Swt.

Pembacaan heuristik pupuh Dhandhanggula bait 14 adalah Allah memiliki sifat yang berbeda dengan makhluk-Nya. Allah hidup tetapi tanpa nyawa dan selama-lamanya tidak akan mati. Umat muslim hendaknya mengetahui bahwa Allah mengetahui alam beserta isinya termasuk mengetahui isi hati umat manusia.

Berikut pembacaan heuristik pupuh Sinom bait 27-28. Nabi Idris mendapat kitab dari Allah Swt. sebanyak tiga puluh, sedangkan Nabi Ibrahim sebanyak sepuluh. Jika dijumlahkan dengan lainnya, maka genap seratus kitab. Empat kitab 
lainnya adalah kitab Taurat, kitab Zabur, Injil, dan Al-Quran. Kitab Zabur merupakan kitab Allah yang diturunkan kepada Nabi Daud, kitab Injil kepada Nabi Isa, dan Al-Quran kepada Nabi Muhammad. Semua kitab ini jelas perintahnya dan juga tidak ada yang berbeda dari semula karena kenabiannya telah dimusyawarahkan dan telah diputuskan di dalam tauhid.

Selanjutnya pembacaan heuristik pupuh Asmaradana bait 4. Seseorang yang ingin mengasihi Nabi, para malaikat, dan para utusan, dia hendaknya terlebih dahulu mengasihi Nabi Rasul Muhammad Mustofa.

Untuk lebih memahami pembacaan heuristik, berikut penerapannya pada pupuh Dhandhanggula bait 35. Dalil hadis menceritakan mengenai kiamat. Ketika seseorang bangkit dari kubur, maka badan orang tersebut masih utuh. Bulunya pun tidak akan berubah. Meskipun sudah lama tidak tumbuh, tetapi akhirnya akan tumbuh kembali.

Selanjutnya yang terakhir, pembacaan heuristik pada pupuh Asmaradana bait 23. Rukun iman yang keenam adalah percaya kepada keuntungan dan kebaikan, kafir dan Islam, kaya dan miskin. Semua ini sudah menjadi ketetapan Allah yang Maha Tinggi.

\section{Pembacaan Hermeneutik}

Pembacaan hermeneutik merupakan lanjutan dari pembacaan heuristik, yaitu teks dibaca ulang agar teks dimengerti dan dipahami. Dari hasil pembacaan heuristik di depan, dapat disimpulkan bahwa teks $S D$ memuat keseluruhan akidah Islam yang bersumber pada enam rukun iman, yakni iman kepada Allah, iman kepada malaikat, iman kepada kitab Allah, iman kepada rasul, iman kepada hari kiamat, dan iman kepada kehendak Allah. Hasil pembacaan heuristik tersebut, selanjutnya 
akan dilakukan pembacaan hermeneutik untuk mengungkapkan makna yang sebenarnya.

\section{Matriks, Model, dan Varian-varian}

Matriks dalam teks $S D$ adalah rukun iman agama Islam. Matriks ini ditransformasikan menjadi model "Darmasonya". Darma berarti kebaikan dan sonya berarti kesunyian. Gabungan dua kata ini dapat dimaknai bahwa dalam keadaan sunyi, seseorang akan mengetahui dan mendapatkan kebaikan. Kebaikan di sini diperolah dari Allah Swt. Karena dalam kesunyian, orang akan lebih dekat dengan Allah. Model itu berupa kiasan atau metafora. Matriks ini sebagai hipogram intern ditransformasikan menjadi varian-varian berupa "masalah" atau "uraian".

Varian pertama adalah iman kepada Allah mengandung makna mempercayai keesaan Allah. Varian kedua adalah iman kepada malaikat yakni percaya bahwa malaikat mendapat kedudukan dan diberi tugas-tugas khusus sesuai dengan bagian masing-masing. Varian ketiga adalah iman kepada kitab Allah, artinya mempercayai dan meyakini kitab-kitab Allah yang diturunkan melalui para utusan-Nya. Varian keempat adalah iman kepada nabi dan rasul memiliki arti mempercayai adanya nabi dan rasul sebagai utusan Allah Swt. Varian kelima adalah iman kepada hari kiamat mengandung makna mempercayai datangnya hari kiamat yang ditandai dengan bangkitnya manusia yang telah meninggal. Varian keenam adalah iman kepada kehendak Allah maksudnya percaya bahwa segala sesuatu yang dikerjakan manusia adalah dengan ukuran dan pengetahuan Allah Yang Maha Tinggi.

Dari matriks, model, dan varian-varian ini, dapat disimpulkan tema "Serat Darmasonya" adalah seseorang yang percaya kepada enam rukun iman, ketika 
dalam kesunyian, dia akan mendapatkan sebuah kebaikan. Kebaikan ini didapatkan dari Allah Swt.

\section{Hubungan Intertekstual}

$S D$ berfungsi sebagai sarana sosialisasi firman Allah kepada pembaca. Sosialisasi di sini menekankan pada aspek keimanan yang bersumber pada enam rukun iman agama Islam. Adapun penjelasan masing-masing aspek keimanan beserta firman Allah sebagai hipogramnya.

Iman kepada Allah mengandung makna mempercayai keesaan Allah Swt. Contohnya terdapat dalam pupuh Dhandhanggula bait 3. Teks ini berhipogram dengan ayat Al-Quran surat Al-Ikhlas ayat 1-4, surat As-Syura ayat 11, dan surat Al-Mu'minun ayat 32.

Iman kepada malaikat berarti percaya adanya malaikat sebagai makhluk Allah yang gaib. Hal ini tampak pada pupuh Sinom bait 14. Teks tersebut berhipogram dengan ayat Al-Quran surat Az-Zumar ayat 75, surat Al-Baqarah ayat 98, dan surat Maryam ayat 16-19.

Iman kepada kitab-kitab Allah artinya mempercayai dan meyakini kitabkitab Allah yang diturunkan melalui para utusan-Nya. Hal ini tampak pada pupuh Sinom bait 28. Teks tersebut berhipogram dengan ayat Al-Quran surat Al-Hadid ayat 25, surat Al-Baqarah ayat 17, dan surat Al-Maidah ayat 68.

Iman kepada rasul Allah artinya mempercayai adanya nabi dan rasul sebagai utusan Allah. Contohnya terdapat pada pupuh Asmaradana bait 4. Teks tersebut berhipogram dengan ayat Al-Quran surat Al-Mukmin ayat 78, surat AtTaubah ayat 62 , dan surat Al-Baqarah ayat 285. 
Iman kepada hari kiamat memiliki makna percaya datangnya hari kiamat. Hal ini tampak pada pupuh Dhandhanggula bait 35. Teks tersebut berhipogram dengan ayat Al-Quran surat Al-Anam ayat 36, surat Abasa ayat 22, dan surat AnNaziat ayat 14 .

Rukun iman yang terakhir adalah iman kepada kehendak Allah, artinya percaya bahwa segala sesuatu yang dikerjakan manusia adalah dengan ukuran dan pengetahuan Allah Yang Maha Tinggi. Hal ini tampak pada pupuh Asmaradana, bait 23. Teks tersebut berhipogram dengan ayat Al-Quran surat At-Talaq ayat 3, surat As-Saba' ayat 36, dan surat An-Najm ayat 48.

\section{Akidah Islam}

Akidah Islam mengacu pada enam keyakinan dasar yang disebut rukun iman, Teks $S D$ mengandung seluruh akidah Islam tersebut. Dari hasil pemaknaan puisi di depan, dapat diuraikan nilai akidah yang terdapat dalam teks $S D$.

\section{1. Pertama, Iman kepada Allah}

Hal ini tampak pada pupuh Dhandhanggula bait 2, 3, 4, 18, 19, dan 20. Makna iman kepada Allah dalam teks-teks tersebut berupa percaya akan ke-Esa-an Allah dan perbedaan antara Allah sebagai Pencipta dengan makhluk sebagai ciptaan-Nya. Beberapa bait yang mengandung iman kepada Allah ini berhipogram dengan ayat Al-Quran surat Al-Ikhlas ayat 1-4, surat As-Syura ayat 11, dan surat Al-Mu'minun ayat 32.

\section{2. Kedua, Iman kepada Malaikat}

Beberapa teks yang mengandung iman tersebut terdapat pada pupuh Sinom bait 12 dan 14. Secara umum, teks-teks tersebut memuat tentang kedudukan, tugas, dan wujud malaikat. Beberapa bait yang mengandung iman kepada malaikat ini 
berhipogram dengan ayat Al-Quran surat Az-Zumar ayat 75, surat Al-Baqarah ayat 98, dan surat Maryam ayat 16-19.

\section{3. Ketiga, Iman kepada Kitab Allah}

Contohnya terdapat pada pupuh Dhandhanggula bait 11, 12, 14, dan pupuh Sinom bait 27-28. Secara umum, teks-teks tersebut memuat keberadaan kitabkitab Allah yakni Taurat, Zabur, Injil, dan Al-Quran yang wajib diimani umat muslim. Bait-bait yang mengandung iman kepada kitab Allah ini berhipogram dengan Al-Quran surat Al-Hadid ayat 25, surat Al-Baqarah ayat 17, dan surat Al-Maidah ayat 68.

\section{4. Keempat, Iman kepada Rasul}

Hal ini tampak pada pupuh Asmaradana bait 4 yang bermakna anjuran mengimani rasul sebagai utusan Allah. Teks ini berhipogram dengan ayat AlQuran surat Al-Mukmin ayat 78, surat At-Taubah ayat 62, dan surat Al-Baqarah ayat 285 .

\section{5. Kelima adalah Iman kepada Hari Kiamat}

Hal ini tampak pada pupuh Dhandhanggula bait 35. Secara umum, teks tersebut mengandung makna kebangkitan manusia dari alam kubur. Teks ini berhipogram dengan ayat Al-Quran surat Al-Anam ayat 36, surat Abasa ayat 22, dan surat An-Naziat ayat 14.

\section{6. Keenam, Iman kepada Kehendak Allah}

Teks yang mengandung nilai tersebut, terdapat pada pupuh Asmaradana bait 23. Teks ini berhipogram dengan ayat Al-Quran surat At-Talaq ayat 3, surat AsSaba' ayat 36, dan surat An-Najm ayat 48 .

\section{Simpulan}


Berdasarkan analisis di depan, dapat dirumuskan simpulan sebagai berikut.

Pertama, berbagai unsur ketidaklangsungan ekspresi pada puisi, baik berupa penggantian arti, penyimpangan arti, maupun penciptaan arti ditemukan dalam teks $S D$. Semua bentuk penggantian arti yang meliputi simile, metafora, litotes, personifikasi, sinekdoke pars pro toto, sinekdoke totum pro parte, dan metonimia digunakan pengarang dalam mengkespresikan gagasan pada puisinya. Bentukbentuk penggantian arti ini digunakan dalam rangka fungsi memberikan gambaran yang konkret terhadap objek yang dilukiskan, intensitas makna, dan menghidupkan suasana yang dilukiskan. Penyimpangan arti yang meliputi ambiguitas dan kontradiksi juga ditemukan. Penyimpangan arti digunakan dalam rangka fungsi memberikan ruang kepada pembaca untuk memberi makna sesuai dengan referensinya, mengkritik, dan menghidupkan suasana yang dilukiskan. Berbagai bentuk penciptaan arti yang meliputi pola persajakan, enjambement, homologue, dan tipografi, juga ditemukan dalam $S D$. Penciptaan arti digunakan dalam rangka fungsi menimbulkan orkestrasi bunyi atau keselarasan bunyi sehingga menimbulkan keselarasan makna (pola persajakan), intensitas makna dan memusatkan perhatian pada kata berikutnya (enjambemen), menciptakan keselarasan nada, keselarasan makna, dan intensitas makna (homologue), dan memberikan gambaran yang konkret pada objek yang dilukiskan dan mengeraskan makna (tipografi). Unsur-unsur ketidaklangsungan ekspresi tersebut, secara umum mengungkapkan makna akidah yang sesuai dengan ajaran agama Islam. Kedua, beberapa bait teks $S D$ yang menjadi sampel, mengungkapkan nilai akidah yang sangat kental yaitu nilai akidah yang sesuai dengan ajaran agama Islam. Ketiga, eratnya hubungan intertekstual antara bait-bait dalam teks $S D$ dengan ajaran agama 
Islam dalam rangka fungsi sebagai sarana sosialisasi dan sarana pemahaman ajaran tersebut kepada pembaca.

\section{Daftar Pustaka}

Alterbernd, Lynn. 1970. A Handbook for The Study of Poetry. London: The Macmillan Company.

Azra, Azyumardi. 2002. Buku Teks Pendidikan Agama Islam pada Perguruan Tinggi Umum. Jakarta: Direktoral Jenderal Pendidikan Islam Departemen Agama Republik Indonesia.

Baried, Siti Baroroh. 1983. Pengantar Teori Filologi. Jakarta: Pusat Pembinaan dan Pengembangan Bahasa Depdikbud.

. 1994. Pengantar Teori Filologi. Yogyakarta: Badan Penelitian dan Publikasi Fakultas (BPPF) Seksi Filologi, Fakultas Sastra Universitas Gadjah Mada.

Darusuprapto. 1985. "Keadaan dan Jenis Naskah Jawa" dalam Keadaan dan Jenis Sastra Jawa: Keadaan dan Perkembangan Bahasa, Sastra, Etika, Tatakrama, dan Seni Pertunjukkan Jawa, Bali, dan Sunda. Yogyakarta: Proyek Penelitian dan Pengkajian Kebudayaan Nusantara (Javanologi), Direktorat Jenderal Departemen Pendidikan dan Kebudayaan.

Departemen Agama R.I. 1993. Al Quran dan Terjemahannya dengan Transliterasi Arab-Latin. Bandung: Gema Risalah Press.

Keraf, Gorys. 1981. Diksi dan Gaya Bahasa. Yogyakarta: Kanisius \& Nusa Indah. 1995. Argumentasi, Deskripsi, dan Narasi. Jakarta: PT Gramedia.

Magnis-Suseno, Franz. 1996. Etika Jawa Sebuah Analisa Falsafi tentang Kebijaksanaan Hidup Jawa. Jakarta: Gramedia.

Mahfud, Rois. 2011. Al-Islam Pendidikan Agama Islam. Jakarta: Erlangga.

Mahrus. 2009. Aqidah. Jakarta: Direktoral Jendral Pendidikan Islam Departement Agama Republik Indonesia.

Pradopo, Rachmat Djoko. 1995. Beberapa Teori Sastra, Metode Kritik, dan Penerapannya. Yogyakarta: Pustaka Pelajar. 2005. Kajian Stilistika. Yogyakarta: FIB UGM Yogyakarta. 2007. Pengkajian Puisi. Yogyakarta: Gadjah Mada University Press.

Riffaterre, Michael. 1978. Semiotic of Poetry. Bloomington: Indiana University Press.

Robson, S.O. 1994. Prinsip-Prinsip Filologi Indonesia. Jakarta: RUL.

Sastrowardojo, Subagio. 1975. Simphoni. Jakarta: Pustaka Jaya.

Soemowidagdo, Ramli L. 1955. Sedjarah dan Ajaran Islam. Malang: Tripitaka. 
Sosrodirdjo, H.R. Moedjono. 1985. Ungkapan dan Istilah Agama Islam. Jakarta: N.V. Sapdodadi.

Subalidinata, RS. 1994. Kawruh Kasusastran Jawa. Yogyakarta: Yayasan Pustaka Nusatama.

Sudikan, Setya Yuwana, dkk. 2000. Pendekatan Stilistika dalam Puisi Jawa Modern Dialek Using. Jakarta: Pusat Pembinaan dan Pengembangan Bahasa Depdiknas.

Suratmin. 1981. Darmasonya. Jakarta: Proyek Penerbitan Buku Sastra Indonesia dan Daerah.

Suwondo, Tirto. 1994. "Analisis Struktural: Salah Satu Model Pendekatan dalam Penelitian Sastra," Teori Penelitian Sastra. Yogyakarta: Masyarakat Poetika Indonesia, IKIP Muhamadiyah Yogyakarta.

Teeuw, A. 1983. Membaca dan Menilai Sastra. Jakarta: Gramedia.

Tohari, Ahmad. 1993. Bekisar Merah. Jakarta: Gramedia.

Wellek, Rene dan Austin Warren. 1989. Teori Kesusastraan. Terjemahan Melani Budianta. Jakarta: Gramedia. 